\title{
Chronic Prostatitis: The Clinical Pharmacist Role and New Delivery Systems \\ Luisetto $\mathbf{M}^{1^{*}}$ and Nili-Ahmadabadi $\mathbf{B}^{2}$
}

${ }^{1}$ European Specialist in Laboratory Medicine, Hospital Pharmacist's Manager, Italy ${ }^{2}$ Nano Drug Delivery, Chapel Hill, NC, USA

\section{Introduction}

It is clearly known that the prostatic gland is frequently involved in Different pathologies in adults and elderly patients. Benignant or malignant: anatomic of functionally disease. Frequently other condition as bladder dysfunctions can be associated or added to this pathologies or causated by it. Some of these pathologies give low level in patient quality life and reducing in life expectance (malignant). Malignant pathologies start as local disease but can diffused as metastatic interesting other apparatus of the patient (patient frequently show resistance to first line therapy in example hormonal blocks, or different chemiotherapic).

But In all of this pathology we can see a not complete resolution with current medical therapy in all patients and this can be related with the difficulties of some drugs to penetrate adequately in the tissue. In example we can see that I many benignant cases as IPERTROPHIA also fitotherapic produces or dietetic integrator are frequently added by the specialist to the classic drugs politherapy.

This shows that the classic drug therapy can be improved. In example Relapses in bacterial chronic prostatitis are commonly in great number of patient even under the best pharmacological therapies available today. It means that something goes wrong in this kind of therapy.

About bacterial chronic prostatitis we can see that some antimicrobials are used for long time cycle in order to have efficiently concentration of the drugs in a sanctuaries tissue as prostatic but this not gives a healing to the entire patient treated and we can have toxicity not irrelevant. We can have different problems: Antimicrobial activity to cover the bacteria spectrum and the concentration active in the tissue for the right time necessary (Dynamic and kinetics).

The answer today, under this clinical results is: Have the right drugs today, need we knew delivery system to produce rely ERLICH MUGIC BULLET expecifically for prostatic tissue? We think that this clinical and therapeutic need in underestimate by pharmaceutical industries (our opinion). Why is today accepted to give great amount of antimicrobial to cure this kind of disease with high number of relapses (augmented toxicity for the patient and diffusion of resistances). Analysing the literature we can see that adding the clinical pharmacist competence in many medical teams we can have global increase in clinical outcomes [1,2].

For this reason we can think that the same we can have in some pathology with high relapses as chronic prostatitis but also in malignant cases (chemiotherapic and other class of molecule available today) we can see that different chemiotherapic drugs are used but patient with resistance can die by metastatic disease (Different drugs, with different way of action). If we know that there is a problem of ph. Kinetics and dynamics of drugs we must clearly say that we need a really new approach to make possible the drug's efficacy act in site of actions as request for an efficiently therapy. We know that it clear that the drugs vehicle is important as the same drugs and that modifying the molecule we can improve the activity in relevant way also due by different tissue diffusion (In example chinolons) [3-5].
Lipophilic hydrophilic balances great influence the pk. Kinetics as $\mathrm{VD}$ or $\mathrm{T}_{1 / 2}$ but also the profile of linked chemical groups can give new delivery of classic drugs (Other can be acid or basic molecular properties or velocity in metabolism). In example see the activity of some MABS linked with radio isotopes in order to send the radioactivity in specific target reducing the complex toxicity. Expertize of clinical pharmacy added to the medical team and to the pharmaceutical industries can help in finding new efficacy solution in drug delivery.

Medicinal chemistry knowledge added to advanced pharmacokinetics and dynamics, metabolism and Toxicology of clinical pharmacist can drive the pharmaceutical industries in the right direction. The same deep knowledge in resistance mechanism (drugs extrusion from intracellular and other) can be a great tool in drugs design. In example it is showed that some intracellular chemiotherapic are extruded by the cell like a normal poison [6].

The same genomic mechanism of resistances and modified enzymatic level, target modify, can make the difference in clinical outcomes [3]. Observing some relevant literature we can see that if in acute situation we have seen a positive impact in improving clinical outcomes as in ICT medical team due by active participation of the clinical pharmacist we can have same improvement also in chronic condition [7].

\section{Conclusion}

Clinical pharmacist competence added to physician competences in multidisciplinary medical team can be the right instrument to evaluate if a therapy needs a heavy improvement (in example in drug delivery).

\section{References}

1. Bond CA, Raehl CL (2007) Clinical pharmacy service, pharmacy staffing, and hospital mortality rates. Pharmacotherapy 27: 481-493.

2. Luisetto M, Nili-Ahmadabadi B, Cabianca L, Ibne Mokbul M (2016) Steps and Impacts of Pharmaceutical Care and Clinical Pharmacy Development on Clinical Outcomes 2016: A Historical Analysis Compared with Results. Clinicians Teamwork 1: 4-8.

3. Luisetto M (2016) Editorial Efficacy of Oncologic Drug Therapy: Some to Rethink in the Management of the System? JBME 4.

4. Luisetto M, Sahu R (2016) Clinical Pharmaceutical Care: A New Management Health Care Discipline in 2016. UK JPB 4: 63-64.

*Corresponding author: Luisetto M, Pharmacologist, European Specialist in Laboratory Medicine, Hospital Pharmacist's Manager, Italy, Tel: 3402479620; E-mail: maurolu65@gmail.com

Received April 18, 2017; Accepted April 19, 2017; Published April 24, 2017

Citation: Luisetto M, Nili-Ahmadabadi B (2017) Chronic Prostatitis: The Clinical Pharmacist Role and New Delivery Systems. J Bioanal Biomed 9: e151. doi: 10.4172/1948-593X.1000e151

Copyright: @ 2017 Luisetto M, et al. This is an open-access article distributed under the terms of the Creative Commons Attribution License, which permits unrestricted use, distribution, and reproduction in any medium, provided the original author and source are credited. 
Citation: Luisetto M, Nili-Ahmadabadi B (2017) Chronic Prostatitis: The Clinical Pharmacist Role and New Delivery Systems. J Bioanal Biomed 9: e151. doi: 10.4172/1948-593X.1000e151

5. Luisetto M, Francesca C, Giovanni B, Behzad NA (2015) Pharmacist Cognitive Service and Pharmaceutical Care: Today and Tomorrow Outlook. UK J Pharmaceut Biosci 3: 67-72.

6. Luisetto M, Hemmati J, Nili-Ahmadabadi B, Cabianca L, Ibne Mokbul M, et al. (2016) Professional Social Media as an Advanced Instrument to Connect
Between Researchers \& Healthcare Professionals. An Innovative Model for New Scientific Social Network. Clinicians Teamwork 1: 9-14.

7. Nili-Ahmadabadi B, Luisetto M, Nili-Ahmadabadi H (2016) Clinical Impact of Pharmacist Presence in ICU Medical Team on Mortality Rate. Clinicians Teamwork 1: 15-33. 